\title{
Performance of Surge Arrester Installation to Enhance Protection
}

\author{
Mbunwe Muncho Josephine ${ }^{1, *}$, Gbasouzor Austin Ikechukwu² \\ ${ }^{1}$ Department of Electrical Engineering, University of Nigeria, Nsukka, 410101, Nigeria, muncho.mbunwe@unn.edu.ng \\ ${ }^{2}$ Department of Mechanical Engineering, Chukwuemeka Odumegwu Ojukwu University, Uli, 431121, Nigeria, \\ ai.gbasouzor@coou.edu.ng
}

\begin{tabular}{l} 
A R T I C L E I N F O \\
\hline Article history: \\
Received: 22 December, 2016 \\
Accepted: 20 January, 2017 \\
Online: 28 January, 2017
\end{tabular}

Keywords:
Surge
Arrester
Protection
Reliability
Technology

\section{Introduction}

A lightning protector also referred to as a lightning arrestor is a device used on electrical power systems and telecommunications systems to protect the insulation and conductors of the system from the damaging effects of lightning. The typical lightning protector, depending on the sizes, has a high voltage terminal and a ground terminal. When a lightning surge travels along the power line to the protector, the current from the surge is diverted through the arrestor, in most cases to earth [1].

In telegraphy and telephony, a lightning protector is placed where wires enter a structure, preventing damage to electronic instruments within and ensuring the safety of individuals nearby. Smaller versions of lightning protectors, also called surge *Corresponding Author: Mbunwe Muncho Josephine, Department of Electrical Engineering, University of Nigeria Nsukka, +2348036675952;

E-mail: muncho.mbunwe@unn.edu.ng protectors, are devices that are connected between each electrical conductor in power and communications systems and the earth [2]. These prevent the flow of the normal power or signal current to ground, but provide a path over which high voltage lightning current flows, bypassing the connected equipment. The purpose is to limit the rise voltage when a communications or power line is struck by lightning or being close to a lightning strike. If protection fails or is absent, lightning that strikes the electrical system introduces thousands of kilovolts that may damage the transmission lines, and can also cause damage to transformers and other electrical and electronic devices including home appliances [2-4].

Also exceeding the capability of an arrester will crack or puncture the metal-oxide disk(s), in effect reduce the arrester internal electrical resistance, thus, the condition will limit the arrester's ability to survive future system conditions. This 
condition does not jeopardize the insulation protection provided by the arrester, but in an unlikely case of complete failure of an arrester, a line-ground arc will develop and pressure will build up inside the housing of the arrester. This pressure will be safely vented to the outside and an external arc will be established provided the fault current is within the pressure relief fault current capability of the arrester. This low-voltage arc maintains equipment protection. Once an arrester has safely vented, it no longer possesses its pressure relief/fault current capability and should be replaced immediately. For a given application, the arrester selected should have a pressure/fault current capability greater than maximum short-circuit current available at the intended arrester location. This rating of arrester capability should include appropriate allowances for future growth in the system [37].

Surge arresters when installed are exposed to many physical factors on the earth. These factors that such arresters are exposed to when they are in operation are expected to affect them in one way or the other. These factors are temperature, spacing of the arresters and earth resistance. The villages around the Donga Matung Division of North West Province of Cameroon have the highest annual average number of lightning storms in the Cameroon. On average, between 40 and 90 thunderstorms hit the areas along the Binshua each year, while Nkambe and some villages along the Donga border have an average of less than 10 per year. So, it is easy to understand that surge protection of electrical equipment is a very important part of the electrical system design. Lightning strikes are not the only sources of voltage surges in the electrical system. The following are a few of the more frequently encountered causes of transient voltage surges:

- Surge voltages associated with switching capacitors;

- Surge voltages due to a failure in equipment insulation resulting in a short circuit on the distribution system;

- Surge voltages associated with the discharge of lightning arresters at other locations within the facility.

When capacitors are switched in and out of the circuit, it is possible to get a re-strike when interrupting the capacitor circuit current. A steep-front voltage excursion may be created from each re-strike. These voltage excursions may be high enough to damage rotating machines applied at the same voltage. A surge capacitor applied at the motor terminals can change the steepness of the wave front enough to protect the motor. A short circuit can cause a voltage surge in excess of 3 times the normal line to neutral crest value. The magnitude and steepness of the wave front is not as severe as that of a lightning strike, but can cause damage or weaken motor windings that do not have the higher Basic Impulse Insulation Level (BIL) ratings of other equipment.

When lightning, discharges through an arrester, surge currents are discharged into the grounding terminal. It is very important that substations and overhead lines be protected with wellgrounded shield wires. It is also equally important that the ground system between pieces of equipment be bonded together with interconnected ground wires dedicated to the grounding system. When a surge is released on a line by direct strokes or induced strokes, the stroke travels in both directions from the point where the stroke originated. Wave velocity is an inverse function of the surge impedance. Waves travel on an overhead line at approximately $1000 \mathrm{ft}$. per microsecond, in cables about $300-$ $600 \mathrm{ft}$. per microsecond and in a buried conductor about $300 \mathrm{ft}$. per microsecond. The velocity internal to a rotating machine may be only $25 \mathrm{ft}$. per microsecond [4-8].

The current resulting from a traveling wave is equal to the voltage divided by the impedance, $E / Z$. Wave current is approximately two to four amps per kilovolt of surge voltage. Lightning waves on overhead lines gradually attenuate with travel. When the wave runs into a change in impedance (transformer, another line, etc.), the wave continues in the same direction at a different magnitude. It will also reflect back in the direction from which it came. When a wave $E_{1}$ traveling on surge impedance $Z_{1}$ encounters surge impedance $Z_{2}$, the voltage on the new wave $Z_{2}$ becomes:

$$
E_{2}=E_{1} \frac{2 Z_{2}}{E_{1}+E_{2}}
$$

Note: as the new surge impedance $Z_{2}$ approaches infinity, representative of an open line, $E_{2}=2 E_{1}$.

The reflected wave will actually double in magnitude in its return in the opposite direction. Unless the wave is discharged to ground (lightning arrester connected to ground), the reflected wave can severely damage electrical equipment. Surges produced by lightning have high magnitudes, but their durations are very short. The lightning discharge may reach its crest value in approximately 1 to 20 microseconds and produce conduction flashover voltages of 5 to 20 times normal in 1 microsecond or less. The wave shape is customarily expressed by two intervals associated with the wave geometry. The first time interval is between a virtual zero and crest; the second time interval is between the virtual zero and the half crest value on the wave tail. The wave is defined if the crest value is added to the two time interval designations. For example, a 20000 amp 10 x 20 microsecond current wave rises to a crest of 20000 amperes in 10 microseconds after virtual zero and decays to 10000 amperes in 20 microseconds after virtual zero.

In addition to component failures, it can cause system upset, lost data, erroneous signals and false system operations. Thus, surge arresters should be designed for all bus systems and system configuration to maintain system reliability regardless of the cause or magnitude of these transients. Surge arrester products should be invaluable to any business when planning for protection from unforeseen occurrences $[3,5,9]$. There are different series of surge arrester and where they can be applied in electrical engineering. Below is the list:

- Low-voltage surge arrestor

- Distribution arrestor

- The station type of common valve arrestor

- Magnetic blow valve station arrestor 
- Protection of rotating machine using magnetic blow valve arrester:

- Line Magnetic blow valve arrester:

- DC or blowing valve-type arrester:

- Neutral protection arrester:

- Fiber-tube arrester:

- Plug-in Signal Arrester:

- High-frequency feeder arrester:

- Receptacle-type surge arrester:

- Signal Arrester:

- Network arrester:

- Coaxial cable lightning arrester [5-7].

\section{Related Work}

\subsection{Principles of Surge Arresters (Heading 2)}

Though there are different types and classes of surge arresters, they all work on the same general principle. Surge arrester works by conducting excess voltages from a signal or power-carrying conductor to ground.

\subsection{Surge Arrester Specification}

Most electrical equipment is rated for traveling wave voltage surge capability by the Impulse Test. The Impulse Test is most common and consists of applying a full-wave voltage surge of a specified crest value to the insulation of the equipment involved [6]. The crest value of the wave is called the Basic Impulse Insulation Level (BIL) of the equipment. Each type of electrical equipment has a standard BIL rating. Lightning arresters are coordinated with standard electrical equipment insulation levels so that they will protect the insulation against lightning over voltages [7]. This coordination is obtained by having an arrester that will discharge at a lower voltage level than the voltage required to break down the electrical equipment insulation. Equipment has certain applicable impulse levels or BIL as defined in industry standards [8]. Follow Current, Discharge current and voltage - The follow current is the current which flows from connected supply sources through lightning arrester following the passage of discharge current [11]. From the discharged current, the surge current flows through the arrester after the spark over, while the discharge voltage is the peak value of the voltage appearing between the line terminals and ground, during the passage of the discharge current [5, 9-11].

\subsection{Surge Arresters Characteristics}

The following types of electrical or electronic devices can be used to reduce or limit voltage surges. Some surge suppression systems use multiple technologies, since each method has its strong and weak points. The first six types listed operate primarily by diverting unwanted surge energy away from the protected load, through a protective component connected in a parallel (or shunted) topology. The last two methods also block unwanted energy by using a protective component connected in series with the power fed to the protected load, and additionally may shunt the unwanted energy like the earlier systems. Among the numerous types are [6]:
- Metal Oxide Varistor (MOV)

A metal oxide varistor consists of a bulk semiconductor material (typically sintered granular zinc oxide) that can conduct large currents (effectively short-circuits) when presented with a voltage above its rated voltage. MOVs typically limit voltages to about 3 to 4 times the normal circuit voltage by diverting surge current elsewhere than the protected load. MOVs may be connected in parallel to increase current capability and life expectancy, providing they are matched sets (unmatched MOVs have a tolerance of approximately $\pm 20 \%$ on voltage ratings, which is not sufficient). MOVs have finite life expectancy and "degrade" when exposed to a few large transients, or many smaller transients. As a MOV degrades, its triggering voltage falls lower and lower. If the MOV is being used to protect a low-power signal line, the ultimate failure mode typically is a partial or complete short circuit of the line, terminating normal circuit operation.

When used in power applications, MOVs usually are thermal fused or otherwise protected to avoid persistent short circuits and other fire hazards. In a typical power strip, the visible circuit breaker is distinct from the internal thermal fuse, which is not normally visible to the end user. The circuit breaker has no function related to disconnecting an MOV. A thermal fuse or some equivalent solution protects from MOV generated hazards.

- Transient voltage suppression (TVS) diode

A TVS diode is a type of Zener diode, also called an avalanche diode or silicon avalanche diode (SAD), which can limit voltage spikes. These components provide the fastest limiting action of protective components (theoretically in picoseconds), but have a relatively low energy absorbing capability. Voltages can be clamped to less than twice the normal operation voltage. If current impulses remain within the device ratings, life expectancy is exceptionally long. If component ratings are exceeded, the diode may fail as a permanent short circuit; in such cases, protection may remain but normal circuit operation is terminated in the case of low-power signal lines. Due to their relatively-limited current capacity, TVS diodes are often restricted to circuits with smaller current spikes. TVS diodes are also used where spikes occur significantly more often than once a year, since this component will not degrade when used within its ratings. A unique type of TVS diode (trade names Transzorb or Transil) contains reversed paired series avalanche diodes for bi-polar operation.TVS diodes are often used in high-speed but low power circuits, such as occur in data communications. These devices can be paired in series with another diode to provide low capacitance as required in communication circuits.

- Thyristor Surge Protection Device (TSPD)

A Trisil is a type of thyristor surge protection device (TSPD), a specialized solid-state electronic device used in crowbar circuits to protect against overvoltage conditions. A SIDACtor is another thyristor type of device used for similar protective purposes. These thyristor-family devices can be viewed as having characteristics much like a spark gap or a gas discharged tube (GDT), but can operate much faster. They are related to TVS diodes, but can "breakover" to a low clamping voltage analogous to an ionized and conducting spark gap. After triggering, the low 
clamping voltage allows large current surges to flow while limiting heat dissipation in the device.

- Gas discharge tube (GDT)

A gas discharge tube (GDT) is a sealed glass-enclosed device containing a special gas mixture trapped between two electrodes, which conduct electric current after becoming ionized by a high voltage spike. GDTs can conduct more current for their size than other components. Like MOVs, GDTs have a finite life expectancy, and can handle a few very large transients or a greater number of smaller transients. The typical failure mode occurs when the triggering voltage rises so high that the device becomes ineffective, although lightning surges can occasionally cause dead.

- Selenium Voltage Suppressor (SVS)

It usually has a longer life than a MOV. It is used mostly in high-energy DC circuits, like the exciter field of an alternator. It can dissipate power continuously, and it retains its clamping characteristics throughout the surge event, if properly sized.

- Quarter-Wave Coaxial Surge Arrestor

It is used in RF signal transmission paths, this technology features a tuned quarter-wavelength short-circuit stub that allows it to pass a bandwidth of frequencies, but presents a short to any other signals, especially down towards DC. The pass bands can be narrowband (about $\pm 5 \%$ to $\pm 10 \%$ bandwidth) or wideband (above $\pm 25 \%$ to $\pm 50 \%$ bandwidth). Quarter-wave coax surge arrestors have coaxial terminals, compatible with common coax cable connectors (especially $\mathrm{N}$ or 7-16 types). They provide the most rugged available protection for RF signals above $400 \mathrm{MHz}$; at these frequencies they can perform much better than the gas discharge cells typically used in the universal/broadband coax surge arrestors. Quarter-wave arrestors are useful for telecommunications applications, such as Wi-Fi at 2.4 or $5 \mathrm{GHz}$ but less useful for TV/CATV frequencies. Since a quarter-wave arrestor shorts out the line for low frequencies, it is not compatible with systems which send DC power for a LNB up the coaxial downlink.

\section{- $\quad$ Series Mode (SM) Surge Suppressors}

These devices are not rated in joules because they operate differently from the other suppressors, and they do not depend on materials that inherently wear out during repeated surges. SM suppressors are primarily used to control transient voltage spikes on electrical power feeds to protected devices. They are essentially heavy-duty low-pass filters connected so that they allow $50 / 60 \mathrm{~Hz}$ line voltages through to the load, while blocking and diverting higher frequencies. This type of suppressor differs from others by using banks of inductors, capacitors and resistors that shunt voltage spikes to the neutral wire, whereas other designs shunt to the ground wire.

\subsection{Factors that Affects Surge Arrester}

Surge arresters when installed are exposed to many physical factors on the earth. These factors are temperature, spacing of the arresters and earth resistance. Figure 1 below shows the effect of temperature.

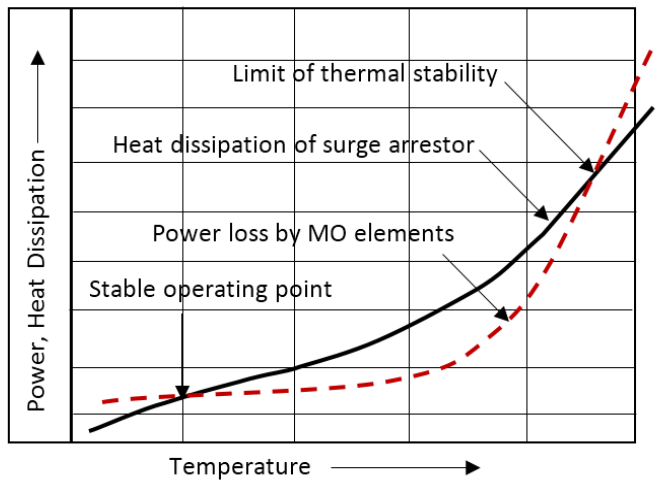

1. Heat dissipation of surge arrestor

2. Power loss by MO elements $-\cdots-\cdot-$

Figure 1.Effect of Temperature

\subsubsection{Effect of Temperature}

Arresters installed today are all metal-oxide (MO) arresters without gaps. $\mathrm{ZnO}$ material has negative thermal coefficient, the heat generation by the MO elements at a constant voltage will increase to a higher degree as the dissipation of this heat through the housing of the arrester. As a consequence, there are two intersections between heat generation and heat dissipation characteristic. After heating the MO elements of the arrester, by single or multiple current impulses, below the limit of thermal stability the arrester will always return to the stable operating point. However, after heating above the limit of thermal stability the arrester will become thermally unstable and be destroyed. The effect of thermal stability is strongly dependent on the thermal properties of the arrester.

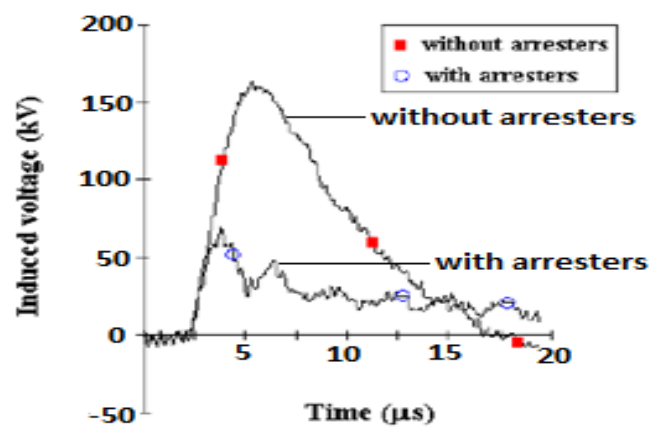

(a)

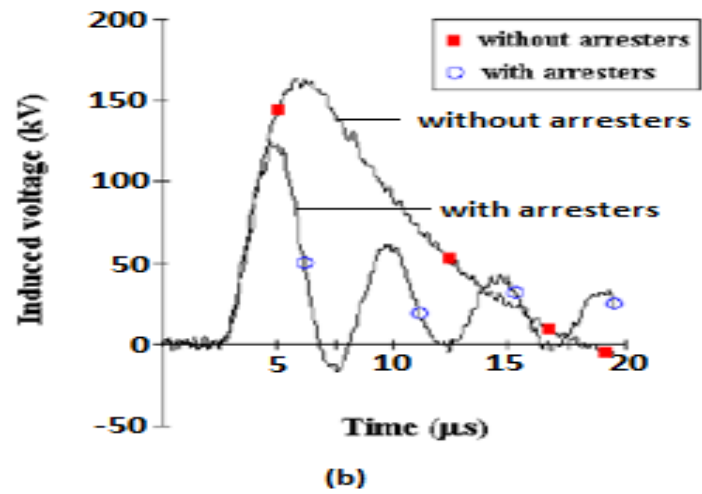

Figure 2. Effect of spacing of arresters 


\subsubsection{Effect of Spacing of the Arresters}

The distance between adjacent surge arrester has influence on the induced voltage particularly if lightning strike point (in the case lightning) is nearly equidistant from the sets of surge arrester. The closer the arresters are, the lower the voltage magnitude will be. The figure 2(a) and 2(b) below compares the induced voltage on line with corresponding arrester spacing of $300 \mathrm{~m}$ and $600 \mathrm{~m}$. The stroke current front time and time to half-value are about $3.2 \mu \mathrm{s}$ and $5.8 \mu \mathrm{s}$, respectively. Figure 2 shows the effect of spacing of the arresters.

Figure 3 comprises the voltage induced on a line without arresters and a line with arrester but with earth resistance of $0 \Omega$ and $200 \Omega$ [9].

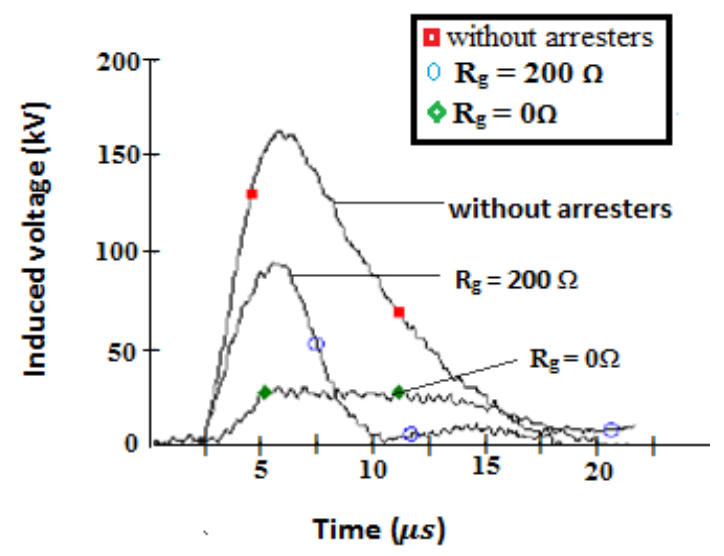

Figure 3.Voltage induced on the lines with and without surge arrester with earth resistance of $0 \Omega$ and $200 \Omega$

The earth resistance may have a significant influence on the induced voltage amplitude, especially when the lightning (in the case of lightning surge) strike point is in front of a set of arresters. This is due to the fact that, for lower value of earth resistance (Rg), the current that flows to earth (through the surge arresters) increasing the value of the voltage component that, by coupling, reduces the induced voltage in the conductors.

\section{Methodology}

\subsection{Presentation of methods for assessing surge arrester performance}

The choice for selecting the arresters is determined by the parameters:

- Surge arrester ratings.

- Impedance division under normal and abnormal conditions to determine whether it will act as low resistive unit under abnormal conditions.

- Selecting station class for its protection capability and distribution class for its restoration capability.

- Also the location of the arrester, determined by the terminal point of the protected equipment.

\subsection{Application and Selection of Surge Arrester}

The objective of arrester selection is to select the lowest rated surge arrester which will provide adequate overall protection of the equipment insulation and have a satisfactory service when connected to the power system. The arrester with the minimum rating is preferred because it provides the greatest margin of protection for the insulation. A higher rated arrester increases the ability of the arrester to survive on the power system, but reduces the protective margin it provides for a specific insulation level. Both arrester survival and equipment protection must be considered in arrester selection. Generally, surge arrester works on the basis of impedance division. Under normal condition it acts as a highly resistive unit but under stress (voltage surge) it acts as a low resistive unit. The mode of operation is best explained using Thevenin theorem. Thevenin theorem states that when a switch is closed in a circuit, the current that flows can be determined by dividing the voltage across the switch prior to closing, by the impedance seen looking into the circuit at the open switch contacts. Consider the figure 4:

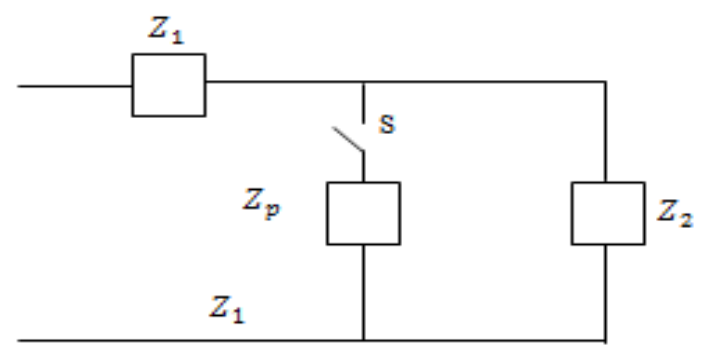

Figure 4. Circuit diagram of surge arrester operation

Suppose $Z_{1}$ is the impedance of a system on which a surge is being generated and that $Z_{2}$ is a piece of equipment connected to the system then $Z_{P}$ is the impedance of the arrester. According to Thevenin, when $\mathrm{S}$ is closed the current through the arrester is given by:

$$
\frac{V}{Z P}+\frac{Z 1 Z 2}{\left(Z 1^{+} Z 2\right)}=\frac{(Z 1+Z 2) V}{\left(Z P Z 1^{+} Z P Z 2^{+} Z 1 Z 2\right)}
$$

And the voltage $V_{1}$ across $Z_{P}$ is given as:

$$
V_{1}=\frac{Z P(Z 1+Z 2) V}{\left(Z P Z 1^{+} Z P Z 2^{+} Z 1 Z 2\right)}
$$

\subsection{Selection of lightning arrester}

The lightning arresters are designated by the crest magnitude of the discharge current having $10 \times 20 \mu s$ wave shape which the arrester can safely pass without causing damage. The lightning arresters are designated as $8,10,20 \mathrm{KA}$ and can safely discharge these current crests. The discharge current from the arrester varies from a few hundred amperes to kilo-amperes Maximum discharge voltage (crest value) and discharge factor for the arrester is defined as the maximum value of voltage which appears across the arrester terminals at the time of discharging if rated current determines its impulse level of protection. The discharge factor is given as in equation 5, to get a result that falls within 2.4 to 3.0:

$$
D F=\frac{v_{d a}}{\mathcal{V}_{r a}}
$$


Where, $v_{d a}=$ discharge voltage of the arrester

$$
\mathcal{V}_{r a}=\text { rated voltage of the arrester }
$$

The above ratio for arresters manufactured by different companies varies from 1.6 to 1.8 , so, the average value may be taken as 1.7 $\mathrm{E}$ rated arrester voltage $\mathrm{KV}$ (R.M.S value) and $\mathrm{L}_{\mathrm{S}}$ as the minimum impulse insulation level in $\mathrm{kV}$ (crest valve) with value after allowing $10 \%$ as tolerance factor and $25 \%$ as margin factor can be obtained.

$$
L_{S}=\frac{1.25 \times 1.1 \times 1.7 \times \sqrt{2}}{0.8} E=4.13 E
$$

In a case of Extra High Voltage (EHV) system, the maximum impulse $\mathrm{L}_{\mathrm{P}}$ in $\mathrm{kV}$ implies:

$\mathrm{L}_{\mathrm{P}}=2.3 \times$ power frequency withstand voltage in $\mathrm{kV}(\mathrm{RMS})$

$$
=2.3 \mathrm{E}_{\mathrm{L}}
$$

For $75 \%$ arrester,

$\mathrm{L}_{\mathrm{P}}=2.37 \mathrm{E}_{\mathrm{L}}$

For $80 \%$ arrester,

$\mathrm{L}_{\mathrm{P}}=2.53 \mathrm{E}_{\mathrm{L}}$

\subsection{Surge current ratings}

The surge current normally is the largest single surge that a device can withstand without damage, should exceed the largest surge that SPD would experience in service. This work uses the largest surge that can be expected at the service entrance as resistance to multiple $3 \mathrm{kA}(8 / 20 \mu s)$ surge for panel protectors. At the service entrance SPD rate the surge current per phase which can be calculated by adding the surge current from individual modes of protection L-N and L-G. Thus, surge current ratings for residential should fall within $10 \mathrm{kA}$ to $70 \mathrm{kA}$ per phase with test waveforms other than $8 / 20 \mu \mathrm{s}$ also acceptable. This work uses surge current ratings of $20 \mathrm{kA}$ to $70 \mathrm{kA}(8 / 20 \mu \mathrm{s})$ per phase. For high-lightning area, like Binshua, SPDs with higher surge current ratings in the range of $40 \mathrm{kA}$ to $120 \mathrm{kA}$ is used in order to provide a longer service life and higher reliability.

\subsection{Lightning Arrester Design}

A station class and intermediate surge arresters are used. The system voltage is $0.415 \mathrm{kV}$ and maximum continuous operation voltage is $48 \mathrm{kV}$ rms. The duty cycle rating is $60 \mathrm{kV}$ rms and maximum discharge current is $10 \mathrm{kA}$.

1. Maximum $0.5 \mu \mathrm{s}$ discharge voltage $=163.5 \mathrm{kV}$

2. Maximum switching surge protective level $=116.4 \mathrm{kV}$

3. Maximum discharge voltage using an $8 / 20=148.8 \mathrm{kV}$

Current wave-kV

The maximum discharge voltage for a10kA impulse current wave produces a voltage wave cresting in $0.5 \mu \mathrm{s}$.
- Specification of Lightning Arrester for Incoming Side Incoming side of residential, the specifications of lightning arrester are as follow.

System nominal voltage $=0.415 \mathrm{kV}$

Rated normal Voltage $=0.415 \times 1.1=45.65 \mathrm{kV}$

Continuous Operating Voltage $(\mathrm{kV}) \mathrm{rms}=48.0 \mathrm{kV}$

Normal Discharge Current ( $8 / 20 \mu \mathrm{s}) \mathrm{kA}=10 \mathrm{kA}$

$1 / 50$ Impulse Spark over Voltage $=163.5 \mathrm{kV}$

Frequency $(\mathrm{Hz})=50 \mathrm{~Hz}$

Type $=$ outdoor

- Specifications of Lightning Arrester for Outgoing Side The followings are the specifications of lightning arrester for outgoing side of residential.

System nominal voltage $=0.220 \mathrm{kV}$

Rated normal Voltage $=0.22 \times 1.1=24.20 \mathrm{kVkV}$

Continuous Operating Voltage $(\mathrm{kV}) \mathrm{rms}=24 \mathrm{kV}$

Normal Discharge Current $(8 / 20 \mu \mathrm{s})(\mathrm{kA})=10 \mathrm{kA}$

Frequency $(\mathrm{Hz})=50 \mathrm{~Hz}$

Type $=$ outdoor

- Intermediate class arrester

Application is based upon the maximum continuous operation voltage, line to neutral, at the arrester location. For grounded neutral systems (GNS), this is computed as:

$$
G N S=\frac{S \mathcal{V}_{m}}{\sqrt{3}}
$$

Where, $S \mathcal{V}_{m}=$ maximum system voltage.

For historical comparison, the maximum continuous operating voltage is $81 \%$ of the conventional $71 \%$ arrester installed on an effectively grounded neutral system.

- Earthing system and Lightning earthing

The frame of every generator, stationary motor, portable motor, and metallic parts of all transformers and the regulating and controlling apparatus connected with supply shall be earthed by separate and distinct connection with earth. Every conductor used on earthing shall be of stranded solid copper or suitable copper alloy, and shall be protected wherever liable to mechanical damage. Also, against corrosion, particular attention being given in these respects to the earthing leads at its point of connection with the earth electrode. The coefficient of earthing is below 80 percent. With earthing coefficient less than $80 \%$ in this case, on four wire distribution systems, the transformer neutral is solidly grounded at every voltage level. On high voltage transmission systems the coefficient of earthing does not exceed $75 \%$. In earthing system, lightning arresters with PVC coated wire and cable lug are used.

- $415 \mathrm{~V}$ Lighting Arrester $\left(70 \mathrm{~mm}^{2}\right.$ PVC Coated Wire $)=$ 50 "

- $220 \mathrm{~V}$ Lighting Arrester $\left(70 \mathrm{~mm}^{2}\right.$ PVC Coated Wire $)=$ 100 "

- $70 \mathrm{~mm}^{2}$ Cable Lug $=2$

\subsubsection{Design Data}

For incoming side and outgoing side, the discharge voltage, insulation level, minimum impulse insulation level and power frequency withstand voltage base on $100 \%$ arrester are as shown 
in Table.1. Ground voltage peak value and switching surge withstand voltage are also shown in Table.1.

Table.1. Design Data Sheet

\begin{tabular}{|l|c|c|}
\hline \multirow{2}{*}{} & \multicolumn{2}{|c|}{ System Voltage } \\
\cline { 2 - 3 } & $\begin{array}{l}\text { Incoming Side of } \\
0.415 \mathrm{kV}\end{array}$ & $\begin{array}{l}\text { Outgoing Side } \\
\text { of 0.220 kV }\end{array}$ \\
\hline Rated Voltage (kV) & 45.65 & 24.20 \\
\hline $\begin{array}{l}\text { Discharge Voltage } \\
\text { on } 100 \% \text { Arrester } \\
(\mathrm{kV})\end{array}$ & 188.76 & 93.6 \\
\hline $\begin{array}{l}\text { Insulation level for } \\
100 \% \text { Arrester }(\mathrm{kV})\end{array}$ & 284.78 & 164.4 \\
\hline $\begin{array}{l}\text { Minimum Impulse } \\
\text { Insulation level on } \\
100 \% \text { (kV) }\end{array}$ & 732.389 & 363.168 \\
\hline $\begin{array}{l}\text { Power Frequency } \\
\text { withstand Voltage } \\
\text { on 100\% (kV) }\end{array}$ & 151.8 & 75.9 \\
\hline $\begin{array}{l}\text { Ground Voltage } \\
\text { Peak Value (kV) }\end{array}$ & 59.28 & 29.63 \\
\hline $\begin{array}{l}\text { Require Switching } \\
\text { Surge withstand } \\
\text { Voltage (kV) }\end{array}$ & 215.6 & 107.8 \\
\hline
\end{tabular}

For the arrester to work properly neither the voltage $\mathrm{V}$ across $\mathrm{S}$ prior to closing nor the voltage $V_{1}$ should exceed the voltage that the equipment is capable of sustaining. The proper selection and application of surge arresters in a system involve impulse test considering the following:

Basic Impulse Insulation Level (BIL), which is the reference insulation level expressed as an impulse crest (or peak) voltage with a standard wave not longer than a $1.2 \times 50$ microsecond wave, that is, the impulse takes 1.2 microseconds to reach the peak and then decays to $50 \%$ of the peak in 50 microseconds. This BIL also have a level that can repeatedly be applied to equipment without flashover, disruptive charge or other electrical failure under test conditions.

Chopped Wave Insulation Level is determined by using impulse waves that are of the same shape as that of the BIL waveform, with the exception that the wave is chopped after 3 microseconds. Generally, it is assumed that the Chopped Wave Level is 1.15 times the BIL level for oil filled equipment such as transformers. However, for dry type equipment, it is assumed that the Chopped Wave Level is equal to the BIL level.

Critical Flashover Voltage, which is the peak voltage for a $50 \%$ probability of flashover or disruptive charge.

Impulses Ratio is the ratio of breakdown voltage at surge frequency to breakdown voltage at normal system frequency, (60 $\mathrm{Hz})$.

Coefficient of Earthlings (CE), which is defined as the ratio of highest rms voltage of healthy phase-to-earth to phase-to-phase normal rms voltage and multiplied by 100 ; that is:

$$
C E=\frac{\mathcal{V}_{\text {Hrms }}}{\mathcal{V}_{\text {LLrms }}} \times 100
$$

Where, $v_{\text {Hrms }}=$ highest rms voltage of healthy line to earth

$$
v_{\text {LLrms }}=\text { normal line to line rms voltage }
$$

The proper selection also involves decisions in three areas:

- Selecting the arrester voltage rating which is based on whether or not the system is grounded and the method of system grounding.

- Selecting the class of arrester, from the three classes of arresters, in order of protection, capability and cost. The classes are: Station class, Intermediate class and Distribution class. The station class arrester has the best protection capability and is the most expensive.

- Determine where the arrester should be physically located.

The rating of the arrester is defined as the RMS voltage at which the arrester passes the duty-cycle test as defined by the reference standard. Metal oxide arresters are designed and tested in accordance with ANSI/IEEE C62.11. This states that, the lower the arrester voltage rating, the lower the discharge voltage, and the better the protection of the insulation system. The lower rated arresters are also more economical. The challenge of selecting and arrester voltage rating is primarily one of determining the maximum sustained line-to-ground voltage that can occur at a given system location and then choosing the closest rating that is not exceeded by it. This maximum sustained voltage to ground is usually considered to be the maximum voltage on the non-fault phases during a single line-to-ground fault. Hence, the appropriate arrester ratings are dependent upon the manner of system grounding. All of the system parameters need to be considered while choosing an arrester classification. If the actual arrester energy duties are not known and a transient study cannot be performed, then it is suggested that Station class arresters be applied. This is a conservative approach that reduces the chances of misapplication.

The ideal location of arresters from the standpoint of protection is directly at the terminals of the equipment to be protected. At this location, with the arrester grounded directly at the tank, frame or other metallic structure which supports the insulated parts, the surge voltage applied to the insulation will be limited to the discharge voltage of the arrester.

When arresters are connected to the power system they continually monitor the system operating voltage, which is referred to as Maximum Continuous Operating Voltage (MCOV). For each arrester rating, there is a limit to the magnitude of voltage that may be continuously applied to the arrester.

For surge arrester applications the "solidly grounded" classification is usually found in electric utility distribution systems where the system is usually only grounded at the point of supply. These systems can exhibit a wide range of grounding coefficients depending upon the system or location in the system. Accordingly, these systems may require a study to ensure the most economical, secure, arrester rating selection. If this information is not known or available, the ungrounded classification should be used. 
The lists arrester ratings, from a manufacturer, that would normally be applied on systems of various line-to-line voltages are as shown in Table 2 [12].

Table 2: Typical Arrester Ratings for System Voltage

\begin{tabular}{|c|c|c|}
\hline \multicolumn{3}{|c|}{ Arrester Rating (kV) } \\
\hline $\begin{array}{c}\text { Norminal System } \\
\text { L-L Voltage } \\
(\mathrm{kV})\end{array}$ & $\begin{array}{c}\text { Grounded } \\
\text { Neutral Circuits }\end{array}$ & $\begin{array}{c}\text { High Impedance } \\
\text { Grounded, } \\
\text { Ungrounded or } \\
\text { Temporarily } \\
\text { Ungrounded }\end{array}$ \\
\hline 2.4 & 2.7 & 3.0 \\
\hline 4.16 & 3.0 & --- \\
\hline & 4.5 & 4.5 \\
\hline & & 5.1 \\
\hline 4.8 & 4.5 & --- \\
\hline & 5.1 & 5.1 \\
\hline & --- & 6.0 \\
\hline 6.9 & 6.0 & --- \\
\hline & --- & 7.5 \\
\hline & --- & 8.5 \\
\hline 12.47 & 9.0 & --- \\
\hline & 10 & --- \\
\hline & --- & 12 \\
\hline & --- & 15 \\
\hline $13.2,13.8$ & 10 & --- \\
\hline & 12 & --- \\
\hline & --- & 15 \\
\hline & --- & 18 \\
\hline $23,24.94$ & 18 & --- \\
\hline & 21 & --- \\
\hline & 24 & 24 \\
\hline & --- & 27 \\
\hline 34.5 & 27 & --- \\
\hline & 30 & --- \\
\hline & --- & 36 \\
\hline & --- & 39 \\
\hline 46 & 39 & --- \\
\hline & --- & 48 \\
\hline 69 & 54 & $\begin{array}{l}--- \\
\end{array}$ \\
\hline & 60 & --- \\
\hline & --- & 66 \\
\hline & --- & 72 \\
\hline
\end{tabular}

\subsection{Designing a Home Surge Arrester System}

The design of any surge arrester comes under the same principle which is to ground any excess voltage that comes into the electrical or electronic system. This could be achieved by considering the circuit diagram as shown in Figure 5.

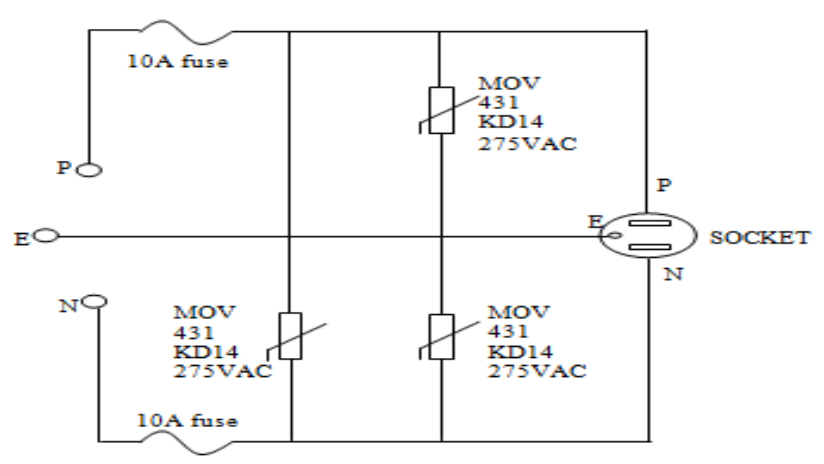

Figure 5. Home Surge Arrester Circuit

From the Figure 4, MOVs are connected in parallel to increase current capability and life expectancy, which, when exposed to a few large transients, or many smaller transients. The MOV degrades, when its triggering voltage falls lower and lower.

When used in power applications, MOVs usually are thermal fused or otherwise protected to avoid persistent short circuits and other fire hazards. In a typical power strip, the visible circuit breaker is distinct from the internal thermal fuse, which is not normally visible to the end user. The circuit breaker has no function related to disconnecting an MOV. A thermal fuse or some equivalent solution protects from MOV generated hazards.

\subsection{Modes of Protection}

The modes of protection required at the service entrance depend on the configuration of the electric distribution system. Surge is transmitted in the normal mode as line-to-neutral (L-N) or line-toline (L-L), or in the common mode as line-to-ground (L-G) or neutral-to-ground (N-G). Immediately after a transformer or at the main entrance, L-N or L-G should be the only protection modes that are required, but into the building, L-N, L-G, and N-G should all be the protection modes required. A simplified surge protection device (SPD) circuit showing how the components are connected is shown in Figure 6.

The entrance protector shown in Figure 6a uses two varistor groups to protect the L-G modes. The L-L modes are protected by the two varistor groups in series. This varistor conduct negligible current until a specific limiting voltage across the terminals is reached. Above that voltage, the device starts to conduct, thereby limiting the voltage across the terminals. The point-of-use protectors, as shown in Figure $6 \mathrm{~b}$ and Figure $6 \mathrm{c}$, uses three varistors to protect all three modes, L-N, L-G, and N-G, as recommended

Since the $\mathrm{N}$ and $\mathrm{G}$ are directly bonded at the service entrance, SPDs used normally have no need to protect the N-G mode. However, protectors downstream from the service entrance or at the load should protect the N-G mode, since N-G surges might arise from downstream in the building. This work effectively uses two varistors in series, each rated for the L-N supply voltage, to provide the L-L limiting voltage. Although the limiting surge 
voltage obtained this way may not be as low as that from separate L-L components, the configuration is usually satisfactory.

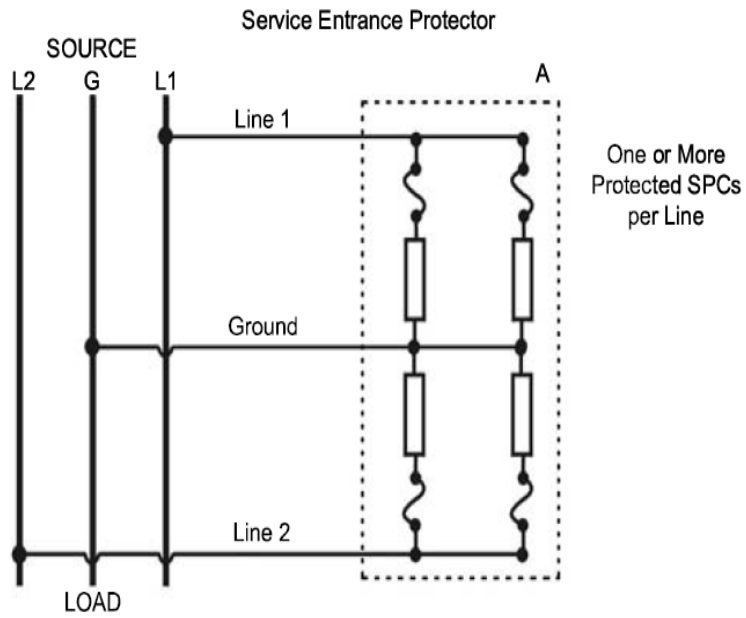

$6(\mathrm{a})$

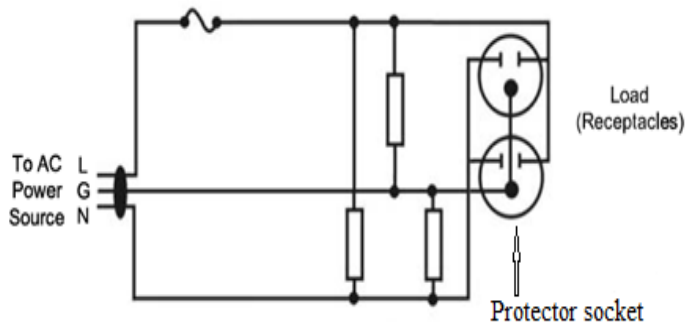

$6(\mathrm{~b})$

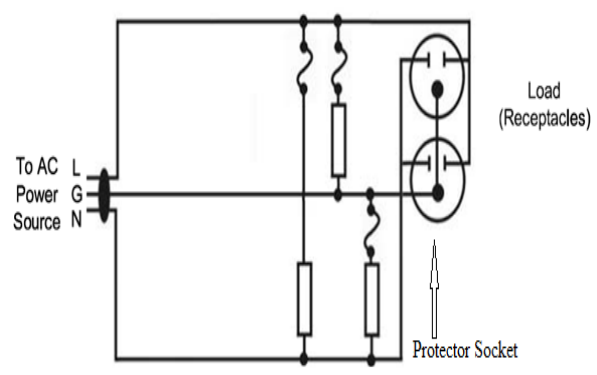

$6(c)$

Figure 6. A simplified surge protection device (SPD) circuit

\subsection{Installation of Home Surge Arrester}

Today's modern homes are filled to the brim with technology products -- from personal music players, e-readers and laptops to HDTVs to hi-tech refrigerators and washing machines. These appliances and electronics feature delicate circuitry that can easily be destroyed by a simple fluctuation in the home's voltage. This can be caused by lightening or a surge in the power grid.

In order to protect these sensitive items, we usually plug their power cords into surge protectors. But, as more electronics become further integrated into our daily lives, we find ourselves having to protect all of them, which makes having surge protectors for every piece of electronics a problem. One way to avoid surge protector overflow is to install a whole-house surge arrester right in your electrical panel. This device will replace one of the existing double-pole circuit breakers in the electrical panel and is relatively easy to install. Although the surge arrester will be technically wired to one circuit, it will protect all of the circuits in the panel. Once your home is protected by the surge arrester, it is still recommended to use surge protectors with your most sensitive equipment as an extra safety measure.

\section{Conclusion}

In this paper, the basis theory of lightning, lightning shielding and design of lightning arrester are presented. Station class and intermediate arresters are used. The type of arrester is outdoor type. The rated voltages of arresters are $46 \mathrm{kV}$ and $25 \mathrm{kV}$, the maximum discharge current is $10 \mathrm{kA}$ and MCOV are $48 \mathrm{kVrms}$ and $24 \mathrm{kVrms}$. The lightning arrester in this paper is provided for overvoltage protection in a high-lightning area. This paper will help and give the electrical knowledge of the protection system in high-lightning area which coach to the technicians, the professional engineers, the students who are facing the overvoltage condition and protection coordination in highlightning area.

So many standards are listed but none of them guarantee that a protector will provide proper protection in a given application. Each standard defines what a protector should do or might accomplish, based on standardized tests that may or may not correlate to conditions present in a particular real-world situation. A specialized engineering analysis may be needed to provide sufficient protection, especially in situations of high lightning risk.

\section{Conflict of Interest}

The authors declare no conflict of interest.

\section{References}

[1] J. Hernandez, GE Specification Engineer; "Lightning Arresters: A Guide to Selection and application".

[2] Lightning arrester. From Wikipedia, the free encyclopedia www.wikipedia.com.

[3] J.G. Anderson, "Transmission line Reference Book, $345 \mathrm{Kv}$ and above", $2^{\text {nd }}$ edition. EPRI, Palo Alto, CA (1982)

[4] Allan Greenwood, "Electrical transients in power system", Wiley, 1971 - Technology \& Engineering - 544 pages

[5] Surge arrestor. From Wikipedia, the free encyclopedia www.wikipedia.com.

[6] L. Pryor, P.E., GE, Sr. Specification Engineer; "The Application and Selection of Lightning Arresters".

[7] Surge arrester, G31-A75X-X809. www.epcos.com

[8] DEHN + SÖHNE, "Lightning protection guide", 3rd updated edition as of December 2014 www.dehn-international.com

[9] A. Piantini, "Lightning Protection of overhead power distribution lines", $29^{\text {th }}$ international conference on lightning protection June 2008; Uppsala, Sweden.

[10] D. Donovan, "Whole-House Surge Arrester: DIY Installation Guide". http://www.stevejenkins.com/

[11] N. K. Htwe, "Analysis and Design Selection of Lightning Arrester for Distribution Substation", World Academy of Science, Engineering and Technology 482008 .

[12] ANSI/ IEEE 1989, "IEEE Standard for Gapped Silicon-Carbide Surge Arresters for AC Power Circuit". 